Basrah Journal

Of Surgery

Bas J Surg, December, 24, 2018

\title{
MANIPULATION OF FRACTURED NASAL BONES UNDER LOCAL ANESTHESIA, ITS EFFICIENCY AND PATIENT SATISFACTION
}

\section{Sajjad Halboos Mohammed Almansoori}

MB,ChB, FICMS, CABS (ENT), Consultant ENT Surgeon, Al-Sadr Teaching Hospital, Basrah, IRAQ.

\begin{abstract}
The nose is the most prominent structure in human face, making it more susceptible to trauma which may reach more than one third of all facial injuries. Although fracture nose is a common surgical problem, very few studies are conducted in Iraq on it.

The aim of this study is to evaluate the efficiency of local anesthesia in fracture nose manipulation and to assess the degree of patient's satisfaction from the functional and esthetic point of view.

The majority of patients attended ENT department were males (68.5\%) lying in the age group between 21-30 years and the reason for their injuries was personal assault. Waiting for complete resolution of edema results in some complications such as bleeding and pain.

Fracture nose manipulation under local anesthesia gives high degree of satisfaction both for the functional (83.3\%) and esthetic (88.9\%) point of view, so this procedure can be recommended in ENT clinical practice in the view of these results as it is more safe, time saving and cost effective.
\end{abstract}

\section{Introduction}

A s the nose is prominent structure in 1 the face, so it is prone to trauma that may reach $39 \%$ of all facial injuries which if untreated may lead to different functional and esthetic problems ${ }^{1-3}$. Fractured nose is the third most common fracture in human body, and it is the most common facial fracture as the fact that even small force may cause it and even a minor injury may lead to significant disability from both esthetic or functional point of view ${ }^{4-6}$. The majority of nasal fractures either laterally displaced or depressed once ${ }^{7}$.

Fracture nose mainly occurs due to assaults, sport injuries, personal or road traffic accidents. The severity of the fracture is determined by the velocity of the trauma and its direction ${ }^{1}$. This fracture can be treated by either closed (which could be performed under local or general anesthesia) or by open reduction.
Post reduction deformity may occur that may necessitate another surgical interference in the form of rhinoplasty or septorhinoplasty. These post reduction morbidities could be caused by the presence of pre existing nasal deformities, nasal edema, or associated septal injury not corrected at the time of fracture manipulation ${ }^{7,8}$.

Simple and isolated fractures of the nasal bones can be reduced effectively under local anesthesia if not associated with significant septal deformity ${ }^{9}$. Most office procedures can be performed under local anesthesia which is simple and cheap, not requiring an airway device or special cardiopulmonary monitoring. Its safety is reported with only minor adverse events ${ }^{10}$. The aim of this study is to assess the efficiency of fracture nose reduction under local anesthesia and its acceptance by the patients through pain tolerance. 


\section{Patients and Methods}

Fifty four patients with isolated nasal bone fracture were included in this study in Basrah Teaching Hospital in the period January 2015 to May 2017 for closed manipulation under local anesthesia. The diagnosis was based on clinical examination and radiography of the nasal bones.

After careful history taking, full examination of the patients was done starting from nasal inspection followed by palpation. Anterior rhinoscopy was performed after the application of pledget soaked in $2 \%$ xylocaine with 1:180000 adrenaline that gives good access to the nasal cavity to assess the state of the nasal septum. All patients were sent for x-ray examination of the nasal bones to exclude other maxillofacial bone fractures.

During manipulation, the patient was put on ENT examination chair with supported head, and 6 cc of $2 \%$ xylocaine were injected to induce anesthesia, 1cc between the medial canthus and glabella, 2ccs injected $1 \mathrm{~cm}$ below the infra orbital ridge on each side. All patients received intranasal pledget of $2 \%$ xylocaine with 1: 180000 adrenaline.
Reduction was performed by digital pressure combined with the use of intra nasal elevator or Walsham nasal forceps, then external fixation was performed by using thermoblast. Nasal pack was used only for those with persisted epistaxis . Pain assessment was done by asking the patient to determine its degree whether it is mild, moderate or severe and the patient was asked if he/she would or not to accept the procedure under local anesthesia if needed in the future.

Finally, the patients were seen after one and three months to re-assess the esthetic result by the author and the degree of satisfaction by the patient regarding the shape and function of the nose and if they accept to do the same procedure under local anesthesia again in view of the results obtained.

\section{Results}

Fifty four patients were selected for manipulation of nasal fracture under local anesthesia, they were 37 males (68.5\%) and 17 females (31.5\%) as shown in table I.

Table I : Gender distribution

\begin{tabular}{|l|l|l|}
\hline Gender & No. & Percent \\
\hline Males & 37 & $68.5 \%$ \\
\hline Females & 17 & $31.5 \%$ \\
\hline
\end{tabular}

Regarding age distribution, the common age group in this study was between 21 and 30 years, as shown in table II.

Table II : Age distribution

\begin{tabular}{|l|l|l|}
\hline Age in years & No. & Percent \\
\hline $11-20$ & 14 & $25.9 \%$ \\
\hline $21-30$ & 25 & $46.3 \%$ \\
\hline $31-40$ & 9 & $16.7 \%$ \\
\hline $41-50$ & 6 & $11.1 \%$ \\
\hline
\end{tabular}

Table III, shows the causes of nasal bone fracture for those attended the office, the commonest cause of trauma was violence (40\%) followed by sport injuries (18.5\%). 
Table III: Causes of nasal fracture

\begin{tabular}{|l|l|l|l|l|}
\hline Cause of fracture & Males & Females & Total & $\%$ \\
\hline Violence & 14 & 8 & 22 & 40 \\
\hline Sport & 10 & 0 & 10 & 18.5 \\
\hline Fall & 8 & 5 & 13 & 24 \\
\hline RTA & 5 & 4 & 9 & 16.7 \\
\hline
\end{tabular}

Most of the patients in this study (74\%) felt mild pain during reduction, Severe pain needed a booster dose of local anesthesia as shown in table IV.

\section{Table IV : Problems during reduction}

\begin{tabular}{|l|l|l|}
\hline Problems & No. & $\%$ \\
\hline Pain \\
\hline mild & 40 & 74 \\
\hline moderate & 10 & 18.5 \\
\hline severe & 4 & 7.4 \\
\hline Bleeding \\
\hline no & 42 & 77.8 \\
\hline mild & 12 & 22.2 \\
\hline moderate & 0 & 0 \\
\hline severe & 0 & 0 \\
\hline
\end{tabular}

The degree of functional and esthetic satisfaction by the patients after reduction is outlined in table V.

Table V : Patient's satisfaction in functional and esthetic results

\begin{tabular}{|l|l|l|l|l|}
\hline \multirow{2}{*}{ Satisfaction } & \multicolumn{2}{|l|}{ Functional } & \multicolumn{2}{l|}{ Esthetic } \\
\cline { 2 - 5 } & No. & $\%$ & No. & $\%$ \\
\hline Satisfied & 45 & 83.3 & 48 & 88.9 \\
\hline Moderate satisfaction & 9 & 16.7 & 6 & 11.1 \\
\hline Unsatisfied & 0 & 0 & 0 & 0 \\
\hline
\end{tabular}

\section{Discussion}

Although nasal bones fractures are the most common fractures in facial injuries ${ }^{9}$, but very few studies about this trauma are available in Iraq. In spite of its less complexity, fracture nose can cause functional and esthetic problems that may reach $50 \%$ of the cases ${ }^{11,12}$.

Fracture nose showed male predominance in our community (68.5\%), and only $31.5 \%$ females representing male to female ratio of 2.2:1, which could be related to the physical activity of males demonstrating their virility and more playing contact sport like football, this result agreed with other studies like
Sharma S et al. who reported male predominance for fracture nose in the form of $72 \%$ males and $28 \%$ females ${ }^{10}$. Another study conducted Raid et al. revealed males predominate females in a ratio of 2.3:11. High incidence of fracture nose was seen in the age group between 21 to 30 years, a similar results recorded by Holt $^{13}$ and Abdulaziz ${ }^{14}$. Dickson and Sharp concluded that fracture nose has the highest incidence at the age of 21 to 30 years ${ }^{15}$. This result is also in our society can be attributed to the high activity of this age group and their presence outside homes for working, 
sports, riding motor cycles or driving cars and hence they are more exposed to such troubles. The relative high number in females fracture nose due to violence that could be attributed to the instability of the marital status in this age group, while no nasal trauma due to sport injuries can be explained by the refusal of sport activities for females in general in this society. The majority of cases are due to violence followed by sport injuries which can be explained by lack of jobs and this may obligate this active group to play contact sport to spend their time and empty their energy. This result also proved by Raid MS AL Ani ${ }^{1}$.

Forty (74\%) patients felt mild pain while only four $(7.4 \%)$ developed severe pain which occurred in those patients for whom reduction was done earlier with no complete resolution of edema. Mild and transient bleeding was developed in only 12 patients (22.2\%) during fracture manipulation which could be caused by the incomplete recovery of ecchymosis and edema.

This study revealed a very high degree of satisfaction both for functional (83\%) and esthetic (88.9\%) results. Those less satisfied patients with the functional results $(16.7 \%)$, the reason is attributed to the presence of nasal septal deviation prior to reduction. No patient was dissatisfied.

In conclusion, this study showed that most of the patients attended ENT department with fracture nose are males, lying in the age group of 21 -30 years, and the reason mainly assaults followed by sport injuries. Waiting for complete resolution of edema gives less problems like bleeding and pain during fracture manipulation. Fracture nose reduction under local anesthesia gives high level of satisfaction both from the functional and esthetic point of view giving the conclusion it is safe and effective way of treatment .

\section{References}

1-Raid M.S. Al-Ani, Hussam Haider S. AL-Robaee. Managment of fractured nose. Tikrit Medical journal 2011; 16 (1): 119- 126

2-Bartkiw TP, Pynn BR, Brown DH. Diagnosis and management of nasal fracture, international journal of trauma nursing 1995; 1: 11-18

3- Krishna Prasad Koirala, Vishal Sharma. Post-operativ outcome of closed reduction of fracture nasal bone. International journal of anatomy, radiology and surgery, 2015 oct, vol 4 (4) : 1-4

4-Bruna Borghse, Davis Reis Calderoni, Luis Augusto Passeri . Retrospective analysis of the approach to nasal fractures at Unicamp clinical Hospital. Rev. Bras.Cir. Plast. 2011,26 ( 4) : 608- 12.

5-Ziccardi VB, Braidy H. Management of nasal fractures. Oralmaxillofac surg clin North America. 2009; 21 (2): 203-8.

6-Rubinstein B, Strong EB. Management of nasal fractures. Arch Fam Med. 2009;9 (8) :738-42.

7- Yo santa Rajapakse, Mark Courtney, Adam Bialostocki, Gary Duncan and Graham Morrissey. Nasal fractures: Astudy comparing local and general anesthesia techniques.

8-Terry Hung et al. Patient satisfaction after closed reduction of nasal fracture. Arch facial plast surg. 2007; 9:40-43

9-Atighechi S, Karimi G. Serial nasal bone reduction: A new approachto the management of nasal bone fracture. J Craniofac Surg2009 jan; 20 (1) 49-52

10-Sharma SD, Kwame I, Almeyda J. Patient aesthetic satisfaction with timing of nasal fracture manipulation. Surgery Research and Practice 2014. Available at http://dx.doi.org/10.1155/2014/238520

11- Illum P, Kristensen S, Jorgensen K, Brahe Pederson C. Role of fixation in the treatment of nasal fractures. Clin otolaryngol Allied Sci 1983; 8(3): 191-195

12- Renner GJ. Management of nasal fractures . Otolaryngol Clin North Ammerica 1991;24 (1) 195- 213 13-Holt GR. Immediate open reduction of nasal septal injuries. Ear Nose Throat J 1978; 5: 443 14-Abdulaziz J.Ashoor, Facharzy, Fahmi A. Al Kars. Nasal bone fracture. Saudi Medical Journal 2000; Vol 21(5): 471-474

15-Dickson MG, Sharpe DT. Aprospective study of nasal fractures. J Laryngol Otol 1986 ;100: 543. 